\title{
Friend or foe: an unusual case of small intestinal mass
}

A previously healthy 72-year-old woman presented with a 2-year history of recurrent abdominal pain and bloating. The abdominal symptoms were often associated with food ingestion. No changes in defecation habits were noted. A local hospital diagnosed the patient with a mass in the small intestine and instructed regular follow-ups. The patient decided to seek further treatment at our facility and was scheduled for a small-intestine computed tomography (CT) scan with contrast.

The CT scan showed a hyperdense mass in the proximal jejunum ( $\triangleright$ Fig. 1 a), measuring $43 \times 35 \mathrm{~mm}$, with neighboring intestinal dilation ( $\triangleright$ Fig. 1 b). No thickening or enhancement of the small-intestine wall was observed.

Owing to the location of the mass, an antegrade double-balloon endoscopy (DBE) was performed for diagnosis. The scope was advanced to the horizontal part of the duodenum, near the ligament of Treitz, where a large duodenal diverticulum was noted ( $>$ Fig. 2 a). The cavity was obstructed by a disk-shaped, yellow bezoar, with a size of approximately $30 \times 40 \mathrm{~mm}$ ( $\mathbf{F i g . 2}$ b). A combination of endoscopic lithotripsy and lithotomy procedures were performed, and the bezoar was successfully removed ( Fig. 3, - Video 1).

Bezoar is a foreign body that can be found anywhere in the gastrointestinal tract and is usually composed of animal or vegetable material [1]. The condition is more common in patients with predisposed conditions, such as poor gastric motility or previous gastric surgery. The most commonly used treatment for bezoar includes a combination of endoscopic lithotripsy with basket or fragmentation with polypectomy snares.
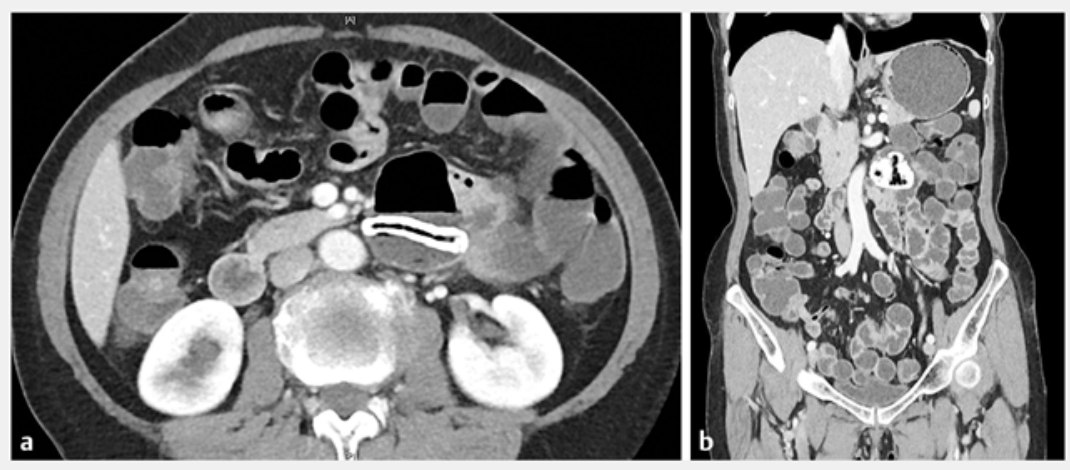

- Fig. 1 Computed tomography scan of the small intestine. a Transverse view. b Coronal view.
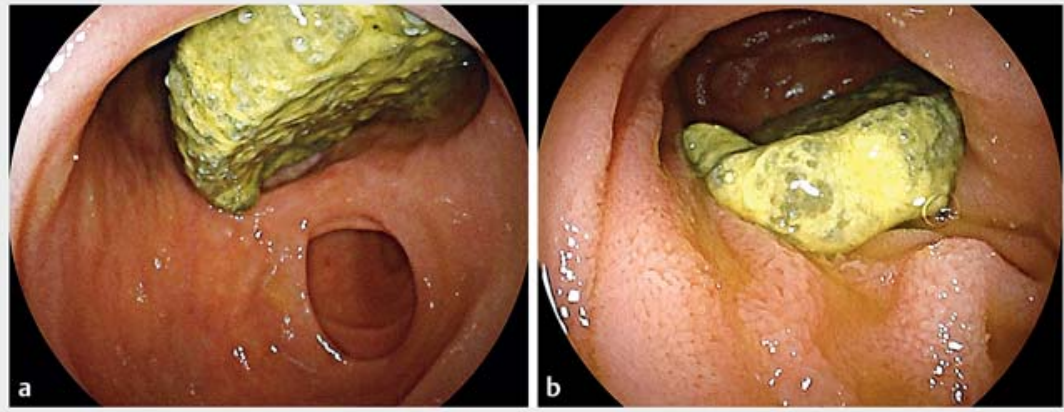

- Fig. 2 Double-balloon endoscopy of the small intestine. a A diverticulum was identified in the distal duodenum. $\mathbf{b}$ A large, disk-shaped bezoar was embedded in the duodenal diverticulum.

Coca-Cola administration to dissolve the bezoar has also been proven to be a cheap and safe alternative [2]. However, due to the predisposed anatomical abnormality in this specific case, combined diverticulectomy may be necessary in the future.

Endoscopy_UCTN_Code_TTT_1AP_2AD

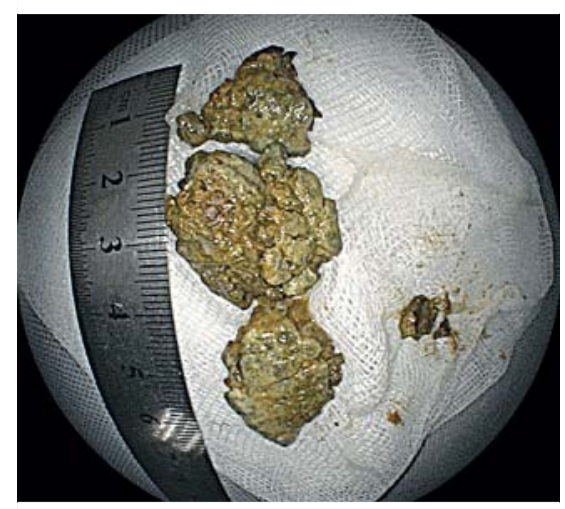

Fig. 3 Removal of the bezoar after intraluminal fragmentation. 


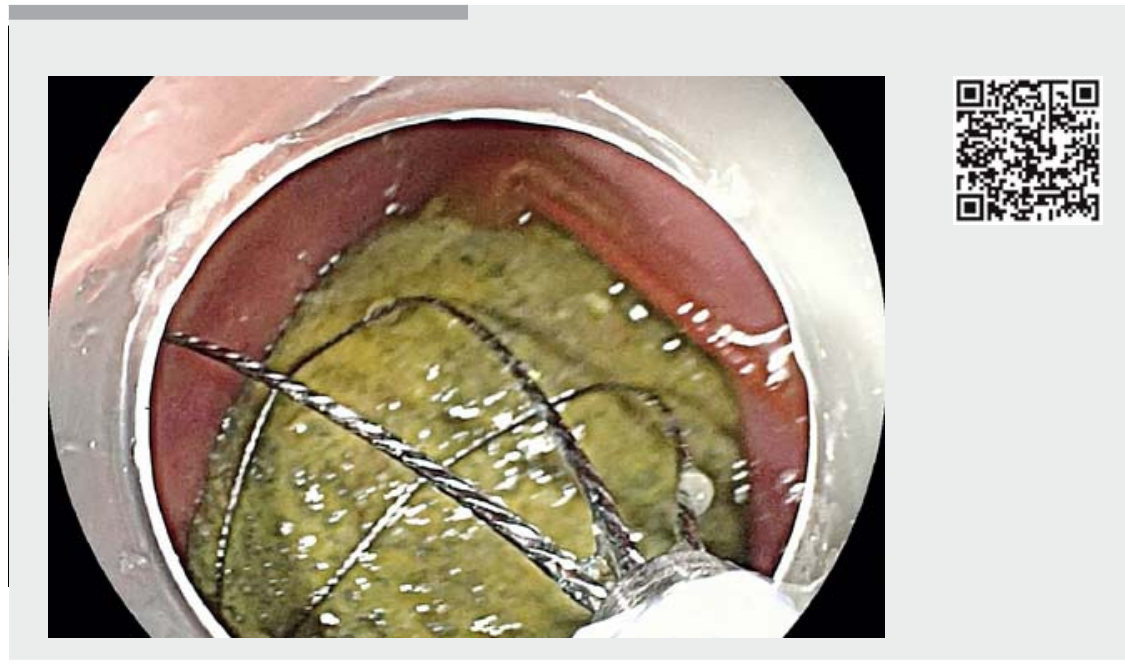

$\checkmark$ Video 1 A double-balloon endoscopy was used for diagnosis of the unidentifiable mass in the small intestine. A large bezoar was located in a duodenal diverticulum. We attempted to remove the bezoar with a combination of lithotripsy and fragmentation.

\section{Acknowledgment}

The present study was funded by the National Natural Science Foundation of China (Grant No. 81500503, Grant No. 81870456).

Competing interests

None

The authors

Yu-jen Tseng, Wei-qun Ding, Liang Zhong, Zhong-guang Luo

Department of Digestive Diseases, Huashan Hospital Fudan University

\section{Corresponding author}

\section{References}

[1] Byrne W]. Foreign bodies, bezoars, and caustic ingestion. Gastrointest Endosc Clin N Am 1994; 4: 99-119

[2] Ladas SD, Kamberoglou D, Karamanolis G et al. Systematic review: Coca-Cola can effectively dissolve gastric phytobezoars as a first-line treatment. Aliment Pharm Ther 2013; 37: 169-173

\section{Bibliography}

DOI https://doi.org/10.1055/a-0861-9980

Published online: 1.4.2019

Endoscopy 2019; 51: E156-E157

(c) Georg Thieme Verlag KG

Stuttgart · New York

ISSN 0013-726X

\section{ENDOSCOPY E-VIDEOS}

https://eref.thieme.de/e-videos

\section{Zhong-guang Luo, MD, PhD}

Department of Digestive Disease, Huashan Hospital, Fudan University, 12 Wulumuqi Middle Road, Shanghai, China, 0086200040 Fax: +86-21-64041990 luozg8@126.com 